\title{
AN ECDM APPROACH FOR THE DEVELOPMENT OF 3D MICROCHANNELS ON GLASS SUBSTRATES
}

\author{
Tarlochan Singh ${ }^{1}$,Akshay Dvivedi ${ }^{2}$ \\ ${ }^{1,2}$ Department of Mechanical and Industrial Engineering Department, Indian Institute of Technology Roorkee, \\ Roorkee 247667, India \\ tsingh.iitr@yahoo.com
}

\begin{abstract}
Microchannels proved to be most favorable component for microfluidic applications. Electrochemical discharge machining provides cost effective solution to produce micro profiles on nonconductive and conductive materials regardless of their hardness, brittleness and surface reflectivity. The present study discusses the effect of applied voltage, electrolyte concentration and workpiece feed rate during fabrication of microchannels on glass substrates. The output parameters studied were material removal rate and microchannel width over cut. The optimum combination of applied voltage $(=50 \mathrm{~V})$, electrolyte concentration $(=$ $20 \%)$ and feed rate $(=16 \mathrm{~mm} / \mathrm{min}$.) yields the best accuracy of the micro channels.
\end{abstract}

Keywords: ECDM, 3D microchannels, glass substrates

\section{INTRODUCTION}

Now days the applications of the microchannels have been extensively used in various diverse and important fields including: bio engineering, micro fluidics, micro heat exchangers, process and power industries, infrared detectors and microelectronics [1-3].Glass is one of the most commonly used materials for micro fluidic applications due to its excellent chemical and heat resistant properties. Various researchers employed several non-conventional machining methods to produce micro channels on glass substrates like micro ultrasonic machining, laser beam machining and abrasive jet machining [4-6]. As compared to other non-traditional machining methods, electrochemical discharge machining (ECDM) is the most promising solution for micron domain subtractive processing of hard and brittle materials. The flexibility to produce $3 \mathrm{D}$ intricate geometries has been reported by various researchers [7].

Basically ECDM is a hybrid non-traditional machining method derived from two non-traditional machining processes namely electric discharge machining and electro chemical machining [8]. In ECDM material removal action takes place owing to the high-temperature melting and chemical etching under the influence of electric discharge energy [9]. The continuous movement of this discharge energy over the workpiece surface generates the $3 \mathrm{D}$ profiles.

In order to generate better quality $3 \mathrm{~d}$ microstructures, there is a need for the effective synchronization of this discharge energy with work feed movements. The present work is dedicated to analyze and discusses the effect of discharge energy controlled process parameters and workpiece feed rate for the fabrication of microchannels on the glass substrates. Applied voltage, electrolyte concentration and workpiece feed rate were considered as the input process parameters to study the material removal rate and channel over cut as an output responses.

\section{MATERIALS AND METHODS}

The detailed description of the house made experimental set up for this work is illustrated in this section. The house made ECDM experimental set-up consists of a pulsed programmable power supply having a voltage variation from 0-70 V with micro to millisecond pulse durations. Electrolyte was filled in a Perspex chamber of size $25 \times 20$ $\times 15 \mathrm{~cm}^{3}$ and base was fixed on the guide block of the worktable. The work material of glass was placed inside the electrolyte chamber and it was fixed by using clamping device. Micro tool of stainless steel material was clamped within the drill chuck that was further connected to the rotary spindle along the $\mathrm{z}$-axis of the machine worktable. The work-piece was feed by the programmable microcontroller against the stationary micro tool while kept both in touch during the experimentation work. Graphite plate was used as an auxiliary electrode. A single layer material removal approach was used to produce $15 \mathrm{~mm}$ straight micro-channels. The machining conditions used in this experimental work are given in Table 1. One factor at a time (OFAT) approach was used to design the experimental plan and to study the influence of applied voltage, electrolyte concentration and workpiece feed rate on material removal rate and over cut. The experiments were performed three times and the average values of these three experiments were taken as the final response. The Material removal rate (MRR) was calculated by using the equation 1 . Material removal rate $=($ Initial weight - final weight $) /$ machining time ( $\mathrm{mg} / \mathrm{min}$.).

Width overcut was measured by using stereomicroscope and calculated by using the equation 2 .

Channel overcut $=$ Channel width - diameter of tool $(\mu \mathrm{m})(2)$ 
Table 1: Machining conditions and their levels

\begin{tabular}{|l|l|l|l|}
\hline S.No. & Process parameter & Units & Levels \\
\hline 1 & Applied Voltage & $\mathrm{V}$ & $50-70$ \\
\hline 2 & Pulse on & $\mathrm{ms}$ & 3 \\
\hline 3 & Pulse off & $\mathrm{ms}$ & 1 \\
\hline 4 & Electrolyte & & $\mathrm{KOH}$ \\
\hline 5 & Concentration & wt./vol. & $10-30$ \\
\hline 6 & Tool diameter & $\mu \mathrm{m}$ & 400 \\
\hline 7 & Feed rate & $\mathrm{mm} / \mathrm{min}$. & $4-20$ \\
\hline 8 & Anode material & & Graphite \\
\hline
\end{tabular}

\section{RESULTS AND DISCUSSION}

Effect of voltage: It was found that the increase in applied voltage increases the impact of discharge energy over the workpiece surface. Consequently this phenomenon leads to increase in material removal rate. Both channel over cut and MRR were observed to be increased with an increase in the applied voltage as shown in Figure 1. Higher applied voltage leads toward the deterioration of micro channel edges and surface quality of the micro channels. In order to maintain the surface accuracy with low edge damages, the applied of 50 volt was selected to perform the further experiments. At 50 volt the measured MRR was 0.47 $\mathrm{mg} / \mathrm{min}$. and the channel overcut was observed $250 \mu \mathrm{m}$.

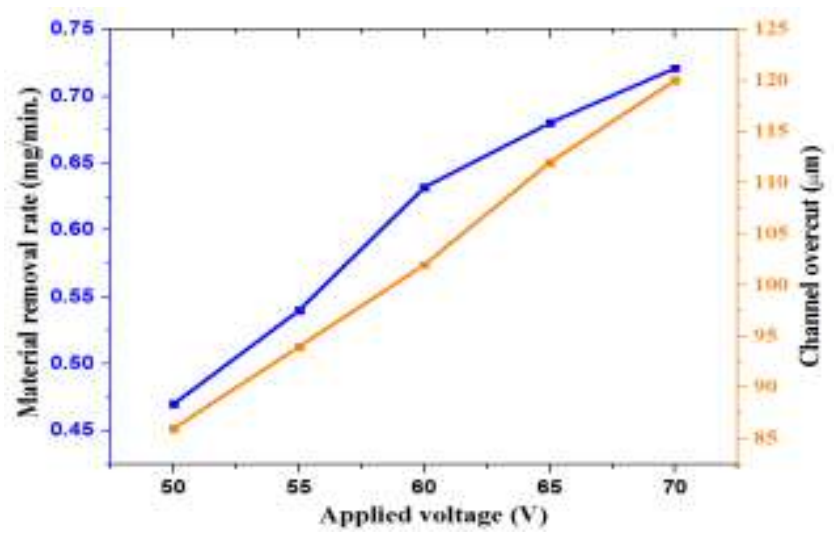

Figure 1: Effect of applied voltage on MRR and channel over cut

Effect of electrolyte concentration: It was observed that an increase in electrolytic concentration of the electrolyte increases the chemical etching phenomenon over the workpiece surface. But, after some typical value, the electrons flow reduces owing to the self restrictions of the ions. An experimental result shows the considerable improvement in material removal rate. An increase in electrolytic concentration increases the MRR and channel over cut as shown in Figure 2. Electrolyte concentration of $20 \%$ (wt. /vol.) was taken as the best parametric setting for the further experimental work.

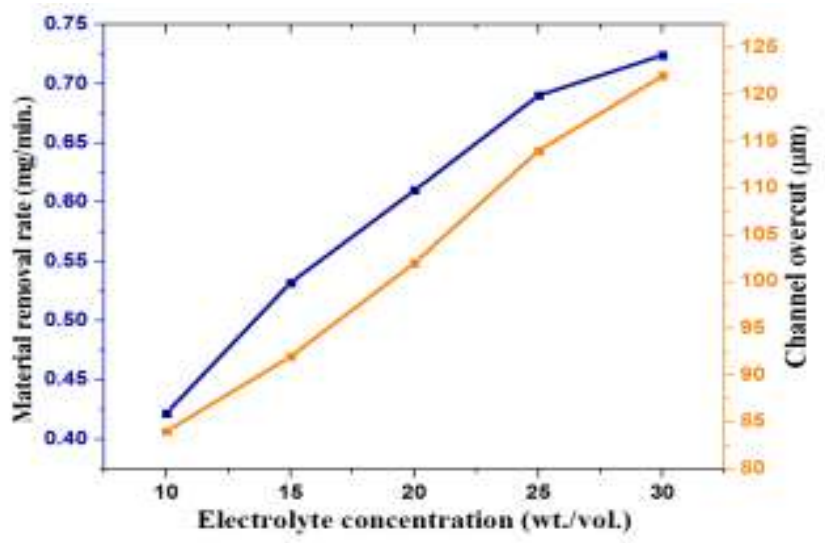

Figure 2: Effect of electrolyte concentration on MRR and channel over cut

Effect of feed rate: Feed rate of workpiece is an important input process parameter during fabrication of micro channels. Basically it is the relative motion between moving work table and stationary tool. It decides the interaction time between discharge energy and the workpiece surface. In this experimental work, the work table was given a feed of 4,8 , 12,16 and $20 \mathrm{~mm} / \mathrm{min}$. For low feed rates, the interaction time will be more that further results in maximum discharge energy for particular workspace. This high discharge energy for particular space results in tool sticking that further caused the deterioration of the microchannel profiles. Moreover, low feed rates also generate the zigzag profiles on the edges of the microchannels. But on the other hand, the higher feed rates results in low depth (approximately 10 to $20 \mu \mathrm{m}$ ) microchannels. So the optimum selection of feed rate can provide the smooth surface microchannels. This experimental work attributes the $16 \mathrm{~mm} / \mathrm{min}$ feed rate for the fabrication of smooth micro channels. The variation trend of material removal rate and channel overcut with respect to feed rate is shown in Figure 3.

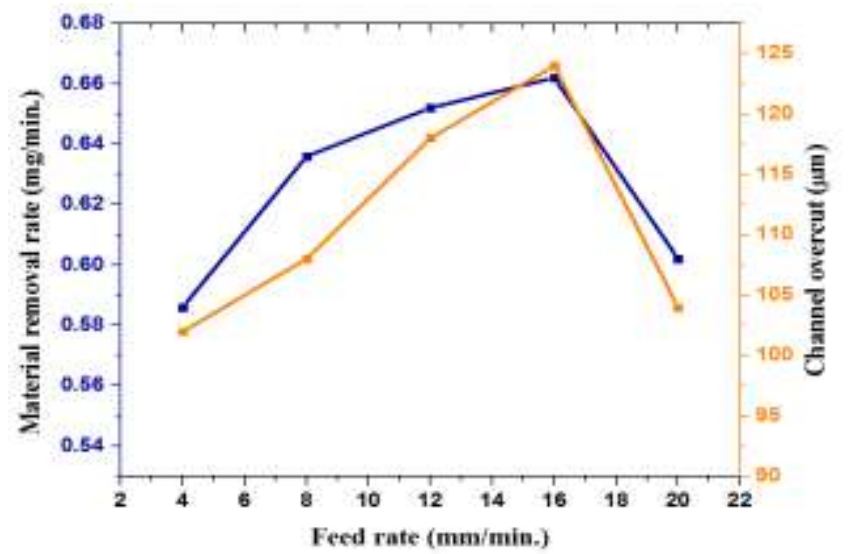

Figure 3: Effect of feed rate on MRR and channel over cut

\section{CONCLUSION}

From this research work it can be concluded that the ECDM having flexibility to fabricate the micron level complex and intricate $3 \mathrm{D}$ shapes on glass materials. Lower ranges of applied voltage reduced the material removal rate but improve the microchannel accuracy. The optimum 
combination of applied voltage $(=50 \mathrm{~V})$, electrolyte concentration $(=20 \%)$ and feed rate $(=16 \mathrm{~mm} / \mathrm{min}$.) yields the best accuracy of the micro channels. By taking such combination a complex micro channel device for micro fluidic applications was fabricated as shown in Figure 4.

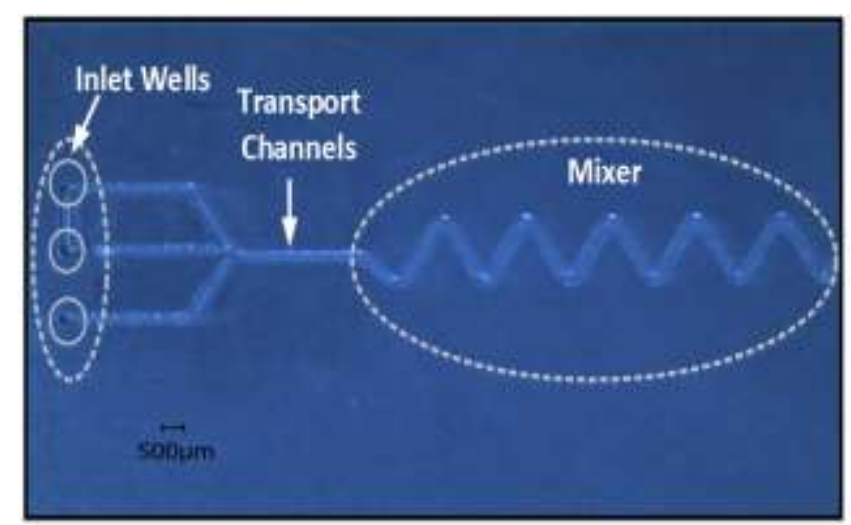

Figure 4: A complex micro channel device for micro fluidic applications

\section{REFERENCES}

[1]. Judy J W (2001) Microelectromechanical systems (MEMS): fabrication, design and applications. Smart materials and Structures 10(6):1115.

[2]. Haeberle S, Zengerle R (2007) Microfluidic platforms for lab-on-a-chip applications. Lab on a Chip 7(9):1094-1110.

[3]. Dario P, Carrozza M C, Benvenuto A, Menciassi A (2000) Micro-systems in biomedical applications. Journal of Micromechanics and Micro engineering 10(2): 235.

[4]. Singh T, Sharma A K, Dvivedi A. (2013) Influence of process parameters during fabrication of SI microchannels using Microultrasonic machining. IManager's Journal on Mechanical Engineering 3(3): 1.

[5]. Shirk M D, Molian P A (1998) A review of ultra short pulsed laser ablation of materials. Journal of Laser Applications 10(1):18-28.

[6]. Yuvaraj N, Pradeep Kumar M (2015) Multiresponse optimization of Abrasive Water Jet cutting process parameters using TOPSIS approach. Materials and Manufacturing Processes 30(7): 882-889.

[7]. Singh T, Dvivedi A (2016) Developments in electrochemical discharge machining: A review on electrochemical discharge machining, process variants and their hybrid methods. International Journal of Machine Tools and Manufacture 105: 1-13.

[8]. Goud M, Sharma A K, Jawalkar C (2016) A Review on Material Removal Mechanism in Electrochemical Discharge Machining (ECDM) and Possibilities to Enhance the Material Removal Rate. Precision Engineering.

[9]. Gupta P K, Dvivedi A, Kumar P. (2014) Developments on electrochemical discharge machining: A review of experimental investigations on tool electrode process parameters. Proceedings of the Institution of Mechanical Engineers, Part B: Journal of Engineering Manufacture, 0954405414534834. 